\title{
Improving E-Bike Safety on Urban Highways in China
}

\author{
Linjun Lu, ${ }^{1}$ Chen Wang, ${ }^{2}$ and Tao Wang ${ }^{3}$ \\ ${ }^{1}$ School of Naval Architecture, Ocean and Civil Engineering, Shanghai Jiao Tong University, Shanghai 200240, China \\ ${ }^{2}$ School of Transportation Engineering, Tongji University, Shanghai 201804, China \\ ${ }^{3}$ School of Transportation, Southeast University, Nanjing 210096, China
}

Correspondence should be addressed to Chen Wang; wkobec@hotmail.com

Received 17 July 2014; Revised 17 September 2014; Accepted 17 September 2014

Academic Editor: Wuhong Wang

Copyright (C) 2015 Linjun Lu et al. This is an open access article distributed under the Creative Commons Attribution License, which permits unrestricted use, distribution, and reproduction in any medium, provided the original work is properly cited.

\begin{abstract}
This paper aims to examine characteristics of e-bike fatal crashes on urban highways in China. Crash data were retrieved from the three-year crash reports (2010-2012) of Taixing City. Descriptive analysis was conducted to examine characteristics of e-bike riders, drivers, and crashes. The important findings include the following: (1) most fatal crashes were related to e-bike riders' aberrant driving behaviors, including driving in motorized lanes, red-light running, driving against the direction of traffic, inattentive driving, and drunk driving; (2) e-bike riders with lower educational background tended to perform illegal or inattentive driving behaviors in fatal crashes; (3) most drivers were not found to commit any faults and very few drivers were found to commit drunk driving offences; (4) most nighttime fatal crashes were related to absence of street lightings; (5) heavy good vehicles (HGVs) and small passenger cars were the two vehicle types that were mostly involved in the e-bike fatal crashes. This study provides useful information that can help traffic engineers better understand e-bike safety in China and develop safety countermeasures.
\end{abstract}

\section{Introduction}

Electric bicycles (i.e., e-bikes) entered China’s market early in 1998 [1]. E-bikes are fully or primarily propelled by electric power from rechargeable batteries. There are different types of e-bikes in China. Among them, the two predominant types are bicycle style e-bikes that are propelled by manual pedaling and electric power together and scooter style e-bikes that are fully powered by electricity [2]. Since they are inexpensive, economic, and convenient, e-bikes have been largely used for daily commute. During the past decade, e-bike ownership has experienced a significant increase in China.

However, despite the above-motioned merits, some serious safety issues on e-bikes have emerged. First, there is no license and insurance required for e-bike riders. Thus, ebike riders with low skills and safety awareness could largely increase traffic risks. Second, there are no mandatory protections required for e-bike riders, such as helmets. Helmets are required for cyclists in many countries and they have been found to effectively protect vulnerable road users, such as bicyclists and motorcyclists. However, although e-bikes have been designed to be faster than bicycles, most e-bike riders in
China do not wear helmets. Third, e-bikes are regulated with the maximum speed of $20 \mathrm{~km} / \mathrm{hr}$. However, many e-bikes, especially scooters, travel at speeds much higher than this limit [3], increasing their crash risk.

In recent years [1], e-bike injuries and deaths have been significantly increasing. Thus, it is essential to examine the related factors of e-bike safety in order to develop effective countermeasures. However, few safety researches on such topic have been identified. To fill this gap, e-bike fatal crashes on urban highways in China are examined in this paper.

\section{Literature Review}

Safety issue is very important for transportation-related research $[4,5]$. However, a limited number of researches on ebike safety have been identified. Weinert et al. [3] examined safety perceptions of e-bike users by surveying e-bike users in Shijiazhuang City in China. Their results included the following: (1) e-bike users felt satisfied and safe when travelling; (2) females felt safer using e-bikes to cross intersections than bicycles. Feng et al. [1] examined the trend of e-bike related injuries in China. It was found that e-bike related injuries and 
deaths were experiencing a significant increase in recent years while overall traffic and bike related injuries and deaths were decreasing. They pointed out that e-bike safety had become a serious problem that deserves more attention in China. Yao and $\mathrm{Wu}$ [6] conducted a self-reported questionnaire survey on e-bike users in two large cities in China. From the responses of e-bike users, they found that gender and automobile driving experiences were highly correlated with atfault e-bike related crashes. Males were found to be more likely to be involved in at-fault crashes than females. Ebike users with driving licenses were found to less likely be involved in crashes. They also found that risk perceptions and safety attitudes of e-bike riders significantly impacted their behaviors in e-bike crashes. Wu et al. [7] examined redlight running behaviors of e-bike users at three signalized intersections in Beijing using video cameras. They identified that age is significantly associated with red-light running behaviors; young and middle-aged e-bike users were more prone to violate traffic rules. Besides, males were more likely to take risks than females at intersections.

Besides, other studies were also found to examine e-bike safety [8-13]. However, most previous studies are focused on driving behaviors of e-bike users. Those research findings provide valuable information for the development of safety interventions and countermeasures. However to our knowledge, there is little research that examines e-bike safety through historical crash data. In order to better understand e-bike safety, it is necessary to examine details of e-bike related crashes. To fill this gap, e-bike related crashes in urban highways in China are examined in this paper.

\section{Data and Method}

Crash data were extracted from the crash reports from the Taixing Police Department. Taixing is a small-sized city with more than 1 million populations in Jiangsu Province. The ebike fatal crash reports from 2011 to 2013 [14-16] were allowed to be accessed for our study purpose. The reports include all e-bike fatal crashes that occurred on urban highways within the Taixing area. For each crash, detailed information was recorded, including crash characteristics, driver information, and road attributes. The data are based on the observations and judgments of the on-scene state and local police officers. There are totally 228 available e-bike fatal crash records during the three years. Note that nonfatal crashes, such as property damage and injury crashes, were not included in the reports. Despite that, the current crash records still include rich information that deserves to be examined. To our knowledge, this is the first statistical analysis on e-bike safety in China, based on real e-bike crash data.

\section{Results}

Limited to the sample size, no obvious crash trend could be identified here. Despite that, the current data source still contains rich information of e-bike fatal crashes. Findings are addressed below.

4.1. Characteristics of E-Bike Riders. Characteristics of e-bike riders were examined and findings are discussed below.

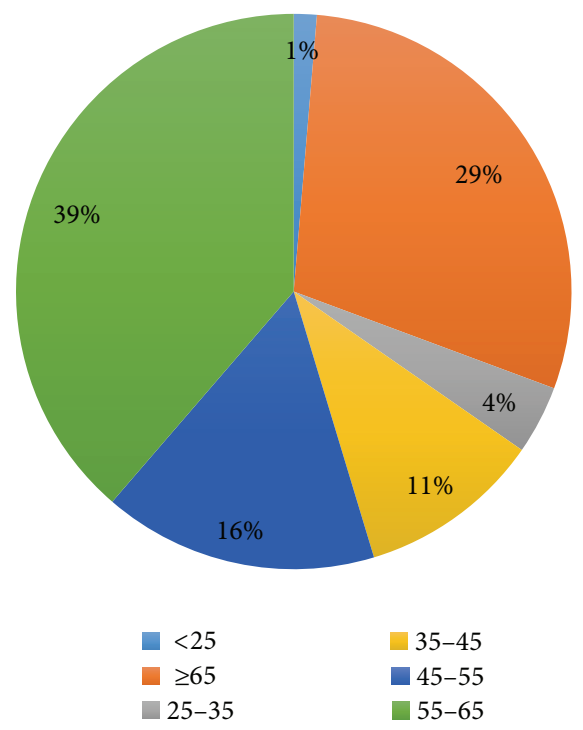

FIGURE 1: Age group of e-bike riders in the e-bike fatal crashes.

4.1.1. Age and Gender. The mean and median age of e-bike riders are 59.2 and 58, respectively. The youngest e-bike rider involved in the fatal crashes was only 15 , while the oldest one was 84. As shown in Figure 1, only 1\% of the crashes involve young e-bike riders (age < 25), while nearly 30\% involve older e-bike riders (age $>65$ ).

This finding seems to be inconsistent with the previous research [6] that young e-bike riders are more likely to be involved in severe crashes than older e-bike riders. The previous research, which was based on surveys, concluded that young e-bike riders were more aggressive than older riders so they were more likely to be exposed to dangerous situations. According to the crash data, a large number of ebike riders, regardless of their age, were identified to directly cross intersections or mid-block openings without carefully watching traffic (i.e., inattentive driving). Older people have more difficulties in reacting and avoiding crashes when they maneuver e-bikes in such manner. Another possible reason is that older e-bike riders may have higher exposure than young e-bike riders. Although exposure data are not available, the current finding suggests that older e-bike riders are more likely to be involved in fatal crashes.

Middle-aged e-bike riders (age between 25 and 65) accounted for the largest percentage (70\%), compared to young and older riders. This could be a reflection of exposure. Males account for $65 \%$ of e-bike fatalities while females account for $35 \%$. This finding is in line with the previous research [6] that male e-bike riders were more likely to be involved in severe crashes than female e-bike riders.

4.1.2. Precrash Behaviors of E-Bike Riders. As shown in Figure 2 , only in $10 \%$ of the crashes, e-bike riders were not found to be at fault (i.e., normal driving). In the other cases, ebike riders were found to perform aberrant driving behaviors, including inattentive driving, red-light running, driving in motorized lanes, driving against the direction of traffic, and drunk driving. 


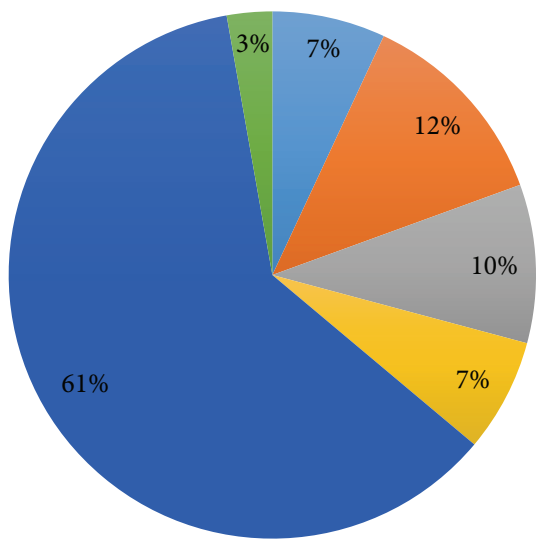

- Drunk driving

- Illegal driving (motorized lane)

- Normal driving

- Red-light running

- Inattentive driving

- Driving against the direction of traffic

FIGURE 2: Precrash behaviors of e-bike riders.

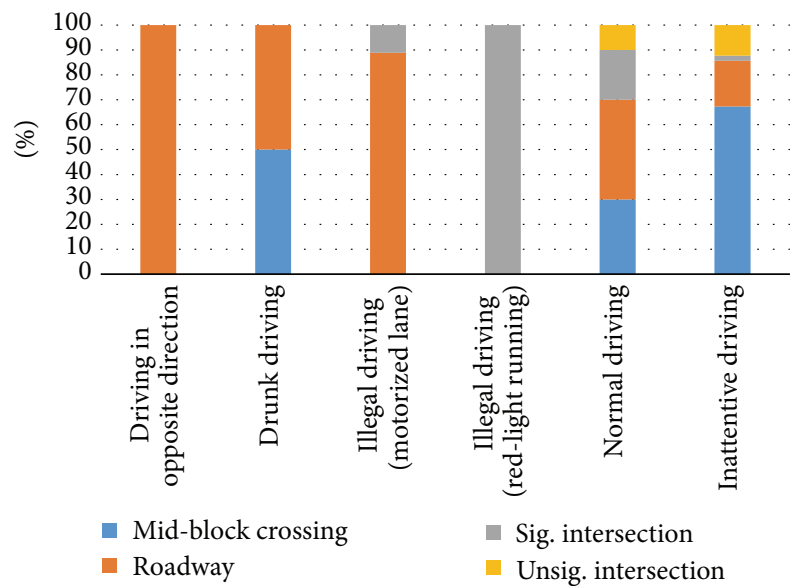

FigURE 3: Breakdown of crash locations for precrash behaviors of e-bike riders.

Inattentive driving (58\%) accounted for the largest percentage of precrash behaviors of e-bike riders. As shown in Figure 3, a large share of inattentive driving was identified at mid-block openings and unsignalized intersections, where e-bike riders were directly passing without decelerating or watching oncoming traffic. Such behavior raises serious safety concerns not only for e-bike riders but also motorized users. Thus, e-bike riders should receive education to increase their safety awareness, especially when they cross intersections and mid-block openings.

$12 \%$ of the crashes were found to involve e-bike riders who were driving in motorized lanes. Notably, there is no case without presence of nonmotorized lanes, suggesting that e-bike riders were not forced to drive in motorized lanes but instead they decided to travel in motorized lanes. This reason could be that there are many local roads in small cities in China, which allow mixed traffic (i.e., multiple modes of transport, including motorized and nonmotorized, share the same roads without physical separation). E-bike riders who oftentimes drive in mixed traffic may subconsciously develop a sense that it is not dangerous to drive in the same lane with vehicles. However, highways are normally designed with much higher speed than local roads, which could significantly increase crash risks and resulting crash severity of such behavior. Moreover, some e-bike riders could be more willing to travel in motorized lanes to get higher speed rather than staying in nonmotorized lanes with bicycles. According to the previous research [15], e-bike riders could feel that bicyclists were the most bothersome while automobiles were the least. In addition, e-bikes were considered to be too fast to drive in the bike lanes according to most bicyclists. Thus, lowering design speed for e-bikes may help reduce e-bike fatal crashes caused by this behavior.

The share of the crashes related to red-light running is $7 \%$. A research was conducted by $\mathrm{Wu}$ et al. [7] on red-light running of e-bike riders at urban intersections. It was found that red-light running was very frequent among e-bike riders, which could somehow explain the high percentage of such crashes.

Driving against the direction of traffic $(3 \%)$ is another traffic violation of e-bike riders which could easily lead to traffic disasters. Such behavior can easily catch drivers off guard and cause severe crashes. The lack of safety awareness and legal awareness has become a serious issue for e-bike users.

Drunk driving (7\%) can be a serious concern for e-bike safety. According to the new traffic law of China [17], drivers who commit drunk driving offence will be heavily punished. This new rule resulted in a significant decrease of drunk driving violations by $35 \%$ [17]. However, when we examined the e-bike related crashes, we surprisingly found that there were a significant number of crashes involving drunk e-bike riders. E-bikes can be operated at maximum of $60 \mathrm{~km} / \mathrm{h}[1]$ which is much higher than other nonmotorized transportation modes (e.g., bicycles). However, there are no laws or rules targeting on punishing drunk e-bike users. If the drunk driving behavior of e-bike riders cannot be strictly banned or controlled, this could be a big threat to e-bike riders, as well as other road users.

4.1.3. Educational Background. According to Figure 4, $87 \%$ of e-bike riders were found to only attend middle schools or lower-level educational institutions. $100 \%$ of older e-bike users (age > 65) only attended middle schools or lower. From Figure 5, e-bike riders who attended high schools or higher-level educational institutions are less likely to exhibit illegal driving or inattentive driving behaviors than e-bike riders with lower educational background. Notably, there are $5 \%$ of e-bike riders who are illiterate. Traditional educational programs are normally targeted on drivers, who are believed to have basic knowledge and understandings of traffic regulations and safety. However, since most e-bike riders only receive education of middle-schools or even lower, special educational programs may need to be considered. Ebike riders may need to receive different levels of educational 


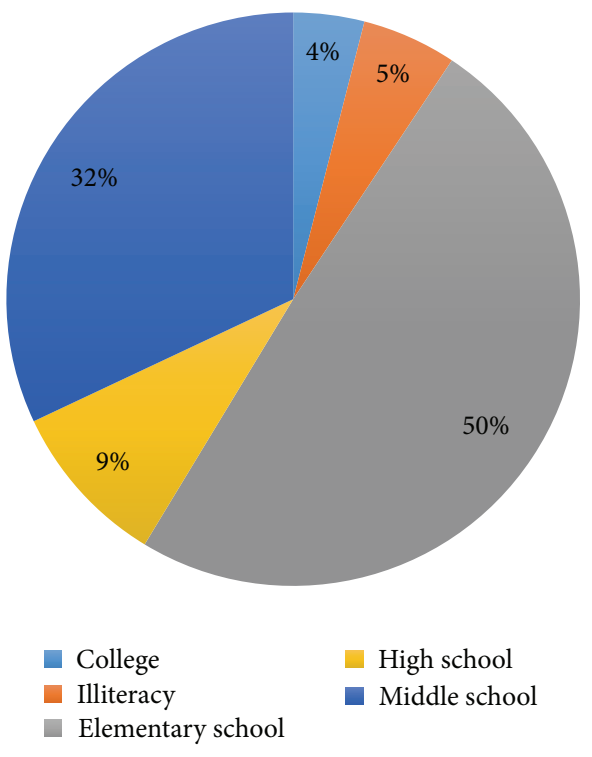

FIgURE 4: Educational background of e-bike riders.

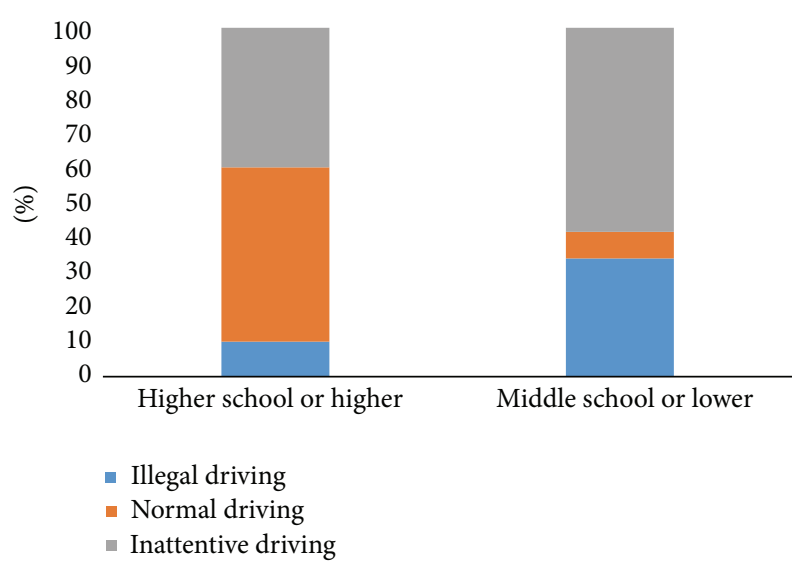

FIGURE 5: Breakdown of precrash behaviors for e-bike riders with different educational background.

programs to increase their safety awareness and legal awareness, depending on their educational background.

\subsection{Characteristics of Drivers. Characteristics of drivers were examined and findings are discussed below.}

4.2.1. Age and Gender. As seen from Figure 6, 34\% of the crashes involved drivers aged between 25 and 35, followed by drivers between 35 and $45(31 \%)$ and between 45 and 55 $(23 \%)$. Note that young drivers (age $<25$ ) only accounted for $7 \%$ and older drivers (age $>65$ ) only accounted for $4 \%$. Middle-aged drivers are a major group involved in the crashes. This could be a reflection of exposure. Male drivers accounted for $92 \%$ while female drivers only accounted for $8 \%$ of the crashes. This could also reflect exposure.

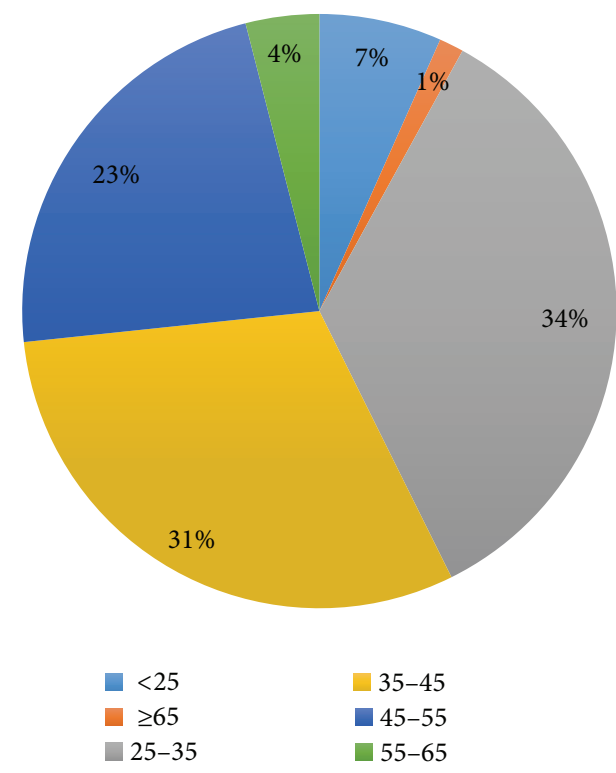

FIGURE 6: Age group of drivers in e-bike fatal crashes.

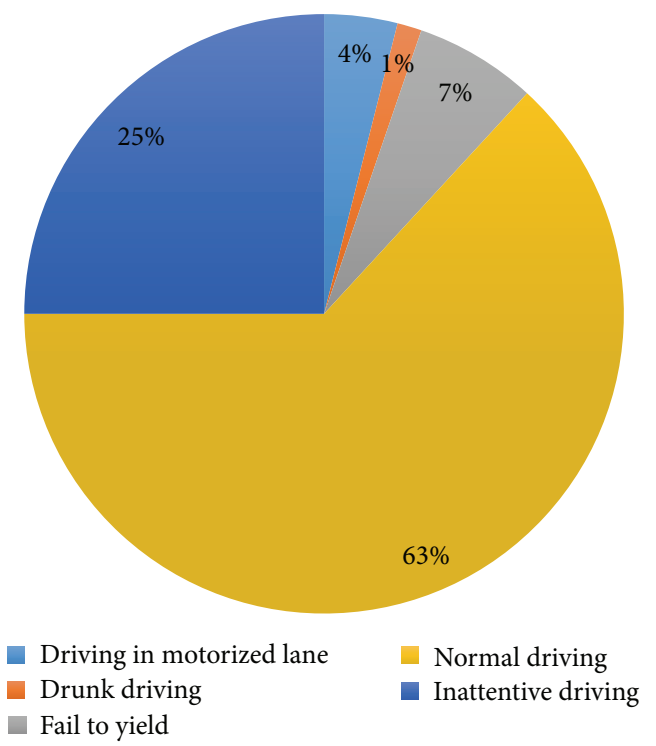

Figure 7: Precrash behaviors of drivers in e-bike fatal crashes.

4.2.2. Precrash Behaviors. From Figure 7, in $63 \%$ of crashes, drivers were not found to have any fault. $25 \%$ of drivers were identified to exhibit inattentive driving behaviors. Inattentive driving was found to be mostly at mid-block openings (Figure 8). Apparently, drivers should pay more attention to ebike riders when they cross mid-block openings. Notably, in some cases it was found that there was no presence of warning signs or pavement markers warning drivers to be cautious and slow down their speed. Considering that e-bikes can be operated at relative high speed, it is very difficult for drivers who are unaware of intersections/mid-block openings to prevent crashes, when e-bikes unexpectedly appear. Thus, investigating road facilities at mid-block openings 


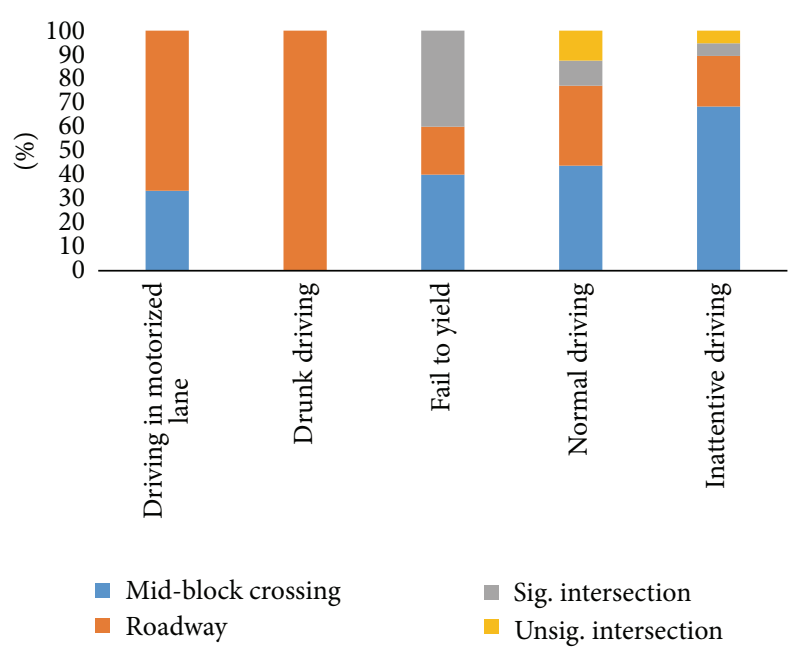

FIGURE 8: Breakdown of crash locations for precrash behaviors of drivers.

and deploying warning signs and devices could help reduce inattentive driving. In addition, no vehicles were determined to commit speeding offence in those cases.

Fail to yield (7\%) is another type of illegal driving behavior that accounted for a considerably large share. Only one case was identified at signalized intersection that the driver committed red-light running offence. Drivers who failed to yield e-bike riders were mostly found at unsignalized intersections and mid-block openings, where e-bike riders have been in the middle of intersection area. Thus, drivers need to be educated to be more cautious and slow down their speed, when they are crossing unsignalized intersections and mid-block openings.

$4 \%$ of the crashes were found to be related to drivers' aberrant behaviors of travelling in nonmotorized lanes. Drivers were found to use nonmotorized lanes for overtaking, according to the latest crash report from the Taixing Police Department [14]. This behavior is considered to be very dangerous to nonmotorized users (e.g., e-bike riders), which should be heavily punished. There are only $1 \%$ of the crashes related to drunk driving. As stated earlier, the new traffic regulation has significantly reduced the number of drunk driving violations of motorized users.

4.3. Characteristics of Crashes. Characteristics of e-bike fatal crashes were examined and findings are discussed below.

4.3.1. Crash Type. As shown in Figure 9, four main crash types were identified: angle, head-on, sideswipe, and rear-end crashes. Among them, angle crashes (51\%) account for more than half of the crashes. As shown in Figure 10, angle crashes mostly happened at intersections and mid-block openings, where e-bike riders were crossing to the other side of roads and collided with oncoming vehicles. Most of inattentive driving behaviors of e-bike riders and drivers were found to be at intersections and mid-block openings. E-bike riders were also identified to commit red-light running violations at signalized intersections.

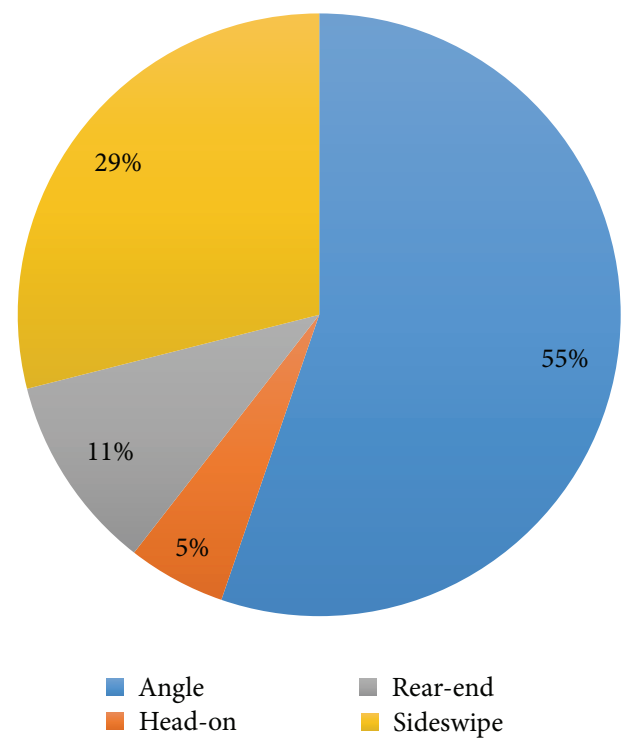

Figure 9: Crash type of e-bike fatal crashes.

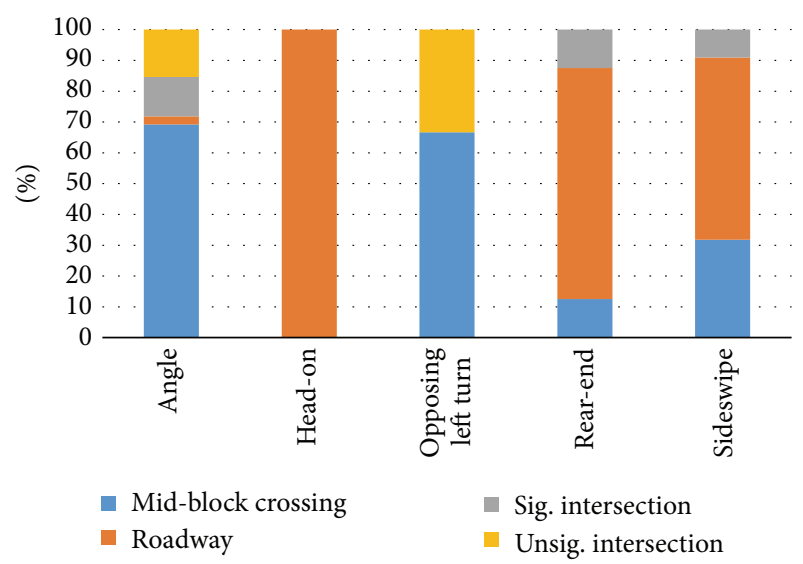

FIGURE 10: Breakdown of crash locations for various crash types.

$29 \%$ of the crashes are sideswipe crashes, which mostly occurred on roadways and at mid-block openings. As stated earlier, some e-bike riders were found to drive in motorized lanes, increasing their probability of being hit by vehicles from the side. Additionally, drivers were identified to use nonmotorized lanes to overtake. In this case, sideswipe crashes could also happen when drivers were trying to make lane changes to nonmotorized lanes.

Rear-end crashes (10\%) mostly happened on roadway sections. Such type of crashes could occur, when drivers are driving in nonmotorized lanes or when e-bike riders are driving in motorized lanes. Thus, to reduce rear-end crashes, safety interventions and law enforcement should be developed to reduce illegal driving behaviors of e-bike riders (i.e., driving in motorized lanes) and drivers (i.e., driving in nonmotorized lanes).

All head-on crashes (5\%) happened on roadway sections, associated with the illegal driving behaviors of e-bike riders 


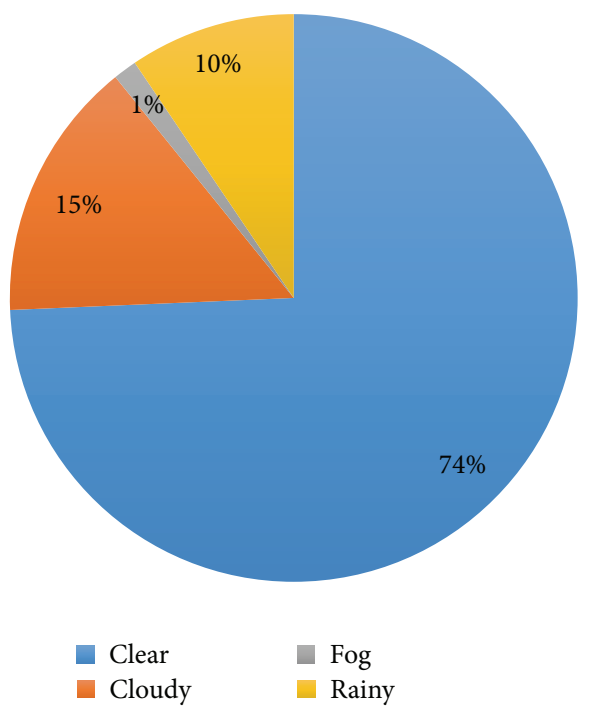

FIGURE 11: Distribution of weather conditions in e-bike fatal crashes.

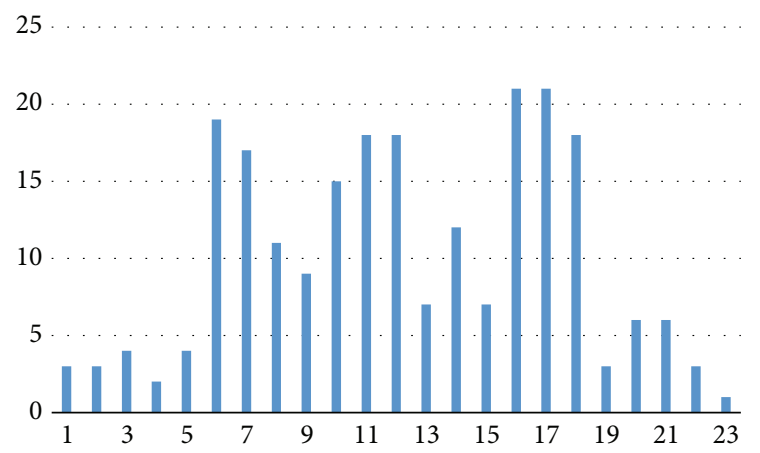

FIGURE 12: Temporal distribution of e-bike fatal crashes.

who travel against the direction of traffic. To our knowledge, one effective way to reduce such crashes is increasing legal awareness of e-bike riders by launching safety campaigns. Law enforcement could also be considered.

4.3.2. Weather and Time. As Figure 11 shows, most crashes (74\%) happened under clear weather. About $15 \%$ of the crashes occurred under cloudy weather, $10 \%$ of the crashes occurred on rainy days, and only $1 \%$ happened under foggy conditions. Figure 12 shows the temporal distribution of the e-bike fatal crashes. In general, it suggests three peak periods: 6:00-8:00 am, 11:00-12:00 am, and 16:00-18:00 pm. Such pattern could be explained by the daily commuting routines in China.

Note that there are a limited number of crashes that happened during late night $(21: 00 \mathrm{pm}-5: 00 \mathrm{am})$. It could be attributed to relatively low traffic volumes during the period. However, most nighttime crashes were found with no presence of street lightings. Thus, it is suggested to investigate lightings at crash-prone locations. E-bike riders are well known to lack safety awareness of wearing reflective clothes

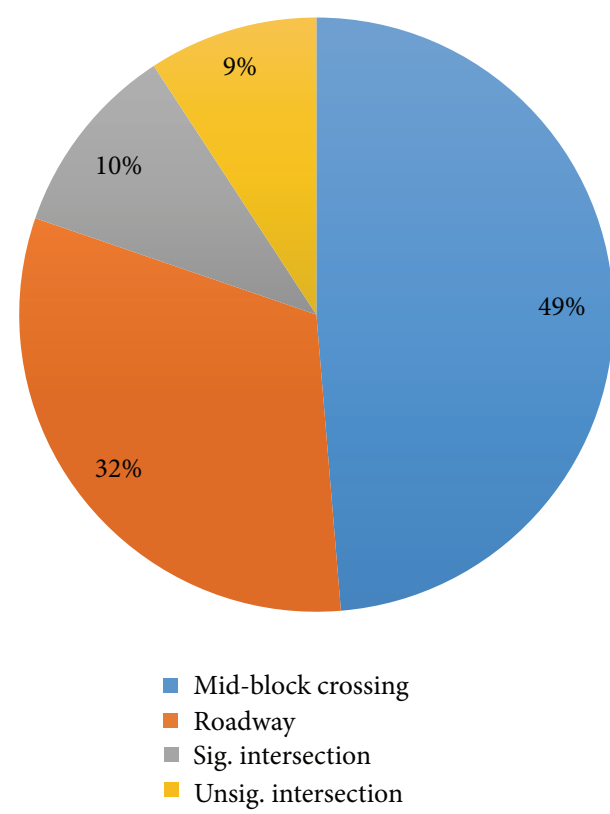

FIGURE 13: Spatial distribution of e-bike fatal crashes.

at night in China. Plus, in some crashes, e-bikes' headlights or brake lights were also found to be malfunctional. Thus, ebike riders are encouraged to wear reflective clothes during the night and regularly investigate lights.

4.3.3. Crash Locations. Seen from Figure 13, $19 \%$ of the crashes happened at intersections. Among these, approximately the half occurred at signalized intersections, while the others were found at nonsignalized intersections. For the crashes at signalized intersections, red-light running and inattentive driving behaviors of e-bike riders were largely found. Besides, inattentive driving and illegal driving (fail to yield) of drivers were also frequently identified. For the crashes at nonsignalized intersections, inattentive driving of both drivers and e-bike riders was found in most cases. In some cases, there was no presence of signs, flashing lights, or speed bumps that warns drivers and e-bike riders. Thus, nonsignalized intersections need to be investigated whether traffic signs or devices are properly installed.

Nearly half of the crashes (49\%) were located at midblock openings. In most cases, there were no warning signs equipped at mid-block openings. Moreover, the crashes at mid-block openings were mostly related to inattentive driving of e-bike riders and drivers. Thus, mid-block openings should be carefully investigated. Warning signs, flashing lights, or speed bumps could be considered to be installed at some locations with high crash frequencies.

$32 \%$ of the e-bike fatal crashes happened on roadway sections. Most of these crashes were found to be rear-end or sideswipe crashes. In many cases, e-bike riders were found to drive in or make a lane change to motorized lanes before crashes. Additionally, drivers were identified to drive in nonmotorized lanes to overtake other vehicles. Consequently, 


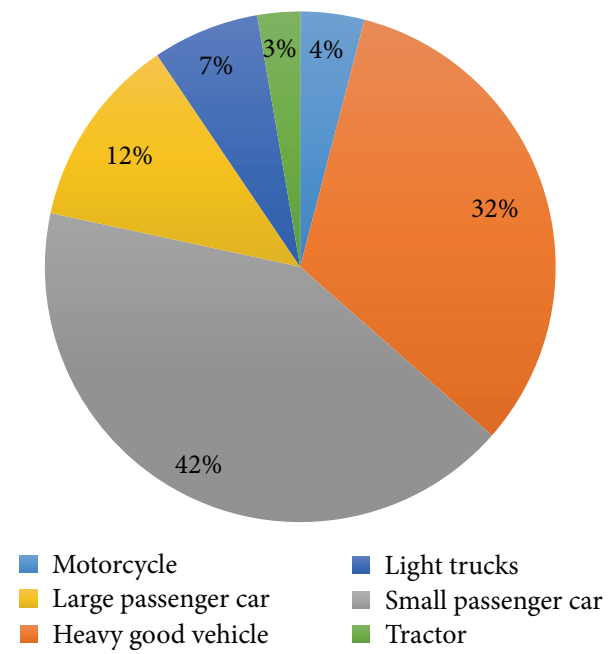

FIgURE 14: Vehicle types in e-bike fatal crashes.

physical separations between motorized and nonmotorized modes could be considered at crash-prone roadway sections.

4.3.4. Vehicle Type. As is shown in Figure 14, heavy goods vehicles (HGVs) and small passenger cars are the two main vehicle types involved in the e-bike fatal crashes. The abrupt crossing maneuvers of e-bike riders could catch drivers off guard. Under such condition, HGVs normally have longer stopping distance and much higher impact forces than other vehicle types, significantly increasing the likelihood of severe injuries. Thus, HGV drivers should be more cautious and slow down their speed when they are crossing midblock openings or intersections, in case e-bike riders appear unexpectedly.

The share of fatal crashes involving small passenger cars is the highest among vehicle types. This could be a reflection of exposure. Other vehicles involved in e-bike fatal crashes include large passenger cars, light trucks, motorcycles, and tractors.

\section{Discussion and Conclusions}

This paper examines the characteristics of e-bike fatal crashes on urban highways in China. The crash reports from the Taixing Police Department were used as the data source. The primary findings of the research include the following.

(1) A large share of fatal crashes involved older e-bike riders and few crashes were found to involve young ebike riders. More male e-bike riders were found than female riders.

(2) Most fatal crashes (90\%) were found to be related to aberrant driving behaviors of e-bike riders, including inattentive driving, driving in motorized lanes, redlight running, driving against the direction of traffic, and drunk driving.
(3) Most e-bike riders were found to be with low educational background (middle schools or lower) and they were found to be more likely to exhibit aberrant driving behaviors, such as inattentive driving and redlight running.

(4) Most fatal crashes were found to involve middle-aged drivers and male drivers.

(5) $63 \%$ of drivers were not found to have any fault before crashes. $25 \%$ of drivers were identified to exhibit inattentive driving behaviors. $7 \%$ of drivers failed to yield to e-bike riders and $4 \%$ of drivers were found to drive in nonmotorized lanes to pass other vehicles. Only $1 \%$ of drivers were found to commit drunk driving offence.

(6) The crashes have four major types: angle, headon, sideswipe, and rear-end. The angle crashes were mostly associated with the inattentive driving of ebike riders and drivers.

(7) Most crashes (74\%) occurred in clear weather conditions. The crashes happened at three peak periods: 6:00 am, 11:00-12:00 am, and 16:00-17:00 pm. Most crashes that happened at nighttime were found to be without presence of street lightings.

(8) $19 \%$ of the e-bike fatal crashes happened at intersections. Half of the crashes occurred at mid-block openings. $32 \%$ of the e-bike fatal crashes were located at roadway sections.

(9) Heavy goods vehicles (HGVs) and small passenger cars were found to be the two major vehicle types in e-bike fatal crashes.

Our findings suggest that e-bike riders need to receive educational programs to raise their safety awareness, when crossing intersections and mid-block openings. Moreover, law enforcement needs to be considered to be targeted on illegal driving behaviors of e-bike riders, such as drunk driving, red-light running, and driving against the direction of traffic. Multilevel educational programs may need to be considered for e-bike riders. Older e-bike riders and loweducated e-bike riders may need to receive special educational and training programs. In addition, e-bike riders are encouraged to wear reflective clothing and investigate ebike lights before they travel during nighttime. Drivers are encouraged to be more cautious and slow down speed near mid-block openings and intersections, especially for HGV drivers. It is necessary to investigate mid-block openings and unsignalized intersections to find if warning signs or speed humps are properly deployed. Street lightings also need to be investigated at crash prone locations.

This study also has some limitations that should be addressed. First, as a descriptive study, it suffers from a common limitation of lacking a reference group [18]. Second, it was only based on fatal crash data, which could limit the generality of the findings to other cities in the world. Third, there are no available exposure data on e-bike riders. Such data could help better understand the crash pattern and safety implications. 
In general, this study provides valuable information on ebike safety on urban highways in China. It is believed that the findings from this research will help safety engineers better understand e-bike safety in China and develop effective safety countermeasures.

\section{Conflict of Interests}

The authors declare that there is no conflict of interests regarding the publication of this paper.

\section{References}

[1] Z. Feng, R. P. Raghuwanshi, Z. Xu, D. Huang, C. Zhang, and T. Jin, "Electric-bicycle-related injury: a rising traffic injury burden in China," Injury Prevention, vol. 16, no. 6, pp. 417-419, 2010.

[2] J. Weinert, C. Ma, and C. Cherry, "The transition to electric bikes in China: history and key reasons for rapid growth," Transportation, vol. 34, no. 3, pp. 301-318, 2007.

[3] J. X. Weinert, M. Chaktan, X. Yang, and C. R. Cherry, "Electric two-wheelers in China: effect on travel behavior, mode shift, and user safety perceptions in a medium-sized city," Transportation Research Record, no. 2038, pp. 62-68, 2007.

[4] Z. Liu and Q. Meng, "Distributed computing approaches for large-scale probit-based stochastic user equilibrium problems," Journal of Advanced Transportation, vol. 47, no. 6, pp. 553-571, 2013.

[5] Z. Liu, Y. Yan, X. Qu, and Y. Zhang, "Bus stop-skipping scheme with random travel time," Transportation Research Part $C$, vol. 35, pp. 46-56, 2013.

[6] L. Yao and C. Wu, "Traffic safety of E-bike riders in China: safety attitudes, risk perception, and aberrant riding behaviors," in Proceedings of the 91st TRB Annual Meeting Compendium of Papers DVD, Transportation Research Board of the National Academies, 2012.

[7] C. Wu, L. Yao, and K. Zhang, "The red-light running behavior of electric bike riders and cyclists at urban intersections in China: an observational study," Accident Analysis and Prevention, vol. 49, pp. 186-192, 2012.

[8] S. Lin, M. He, and Y. Tan, "Comparison study on operating speeds of electric bicycles and bicycles experience from field investigation in Kunming, China," Transportation Research Record, vol. 2048, pp. 52-59, 2008.

[9] C. R. Cherry, J. X. Weinert, and Y. Xinmiao, "Comparative environmental impacts of electric bikes in China," Transportation Research D: Transport and Environment, vol. 14, no. 5, pp. 281290, 2009.

[10] H. Mei, Y. Xiaobao, and J. Bin, "Crossing reliability of electric bike riders at urban intersections," Mathematical Problems in Engineering, vol. 2013, Article ID 108636, 8 pages, 2013.

[11] W. Du, J. Yang, B. Powis et al., "Understanding on-road practices of electric bike riders: an observational study in a developed city of China," Accident Analysis \& Prevention, vol. 59, pp. 319-326, 2013.

[12] J. Dill and G. Rose, "E-bikes and transportation policy: insights from early adopters," in Proceedings of the TRB 91th Annual Meeting Compendium of Papers DVD, Transportation Research Board of the National Academies, 2012.
[13] J. Yang, Y. Hu, W. Du et al., "Unsafe riding practice among electric bikers in Suzhou, China: an observational study," BMJ Open, vol. 4, no. 1, Article ID e003902, 2014.

[14] Taixing Police Department, 2013 Crash Report, 2013.

[15] Taixing Police Department, "2012 Crash Report," 2012.

[16] Taixing Police Department, 2011 Crash Report, 2011.

[17] X. Wang, China's Drunk Driving Cases Down by 35\%, Xinhua Daily, Xinhua, China, 2011.

[18] H. H. Jama, R. H. Grzebieta, R. Friswell, and A. S. McIntosh, "Characteristics of fatal motorcycle crashes into roadside safety barriers in Australia and New Zealand," Accident Analysis and Prevention, vol. 43, no. 3, pp. 652-660, 2011. 


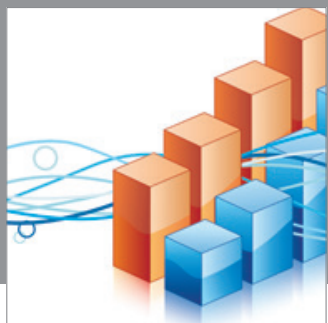

Advances in

Operations Research

mansans

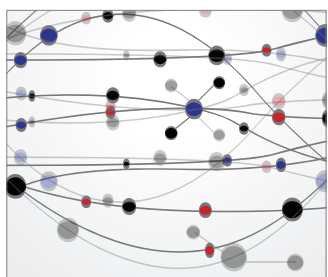

The Scientific World Journal
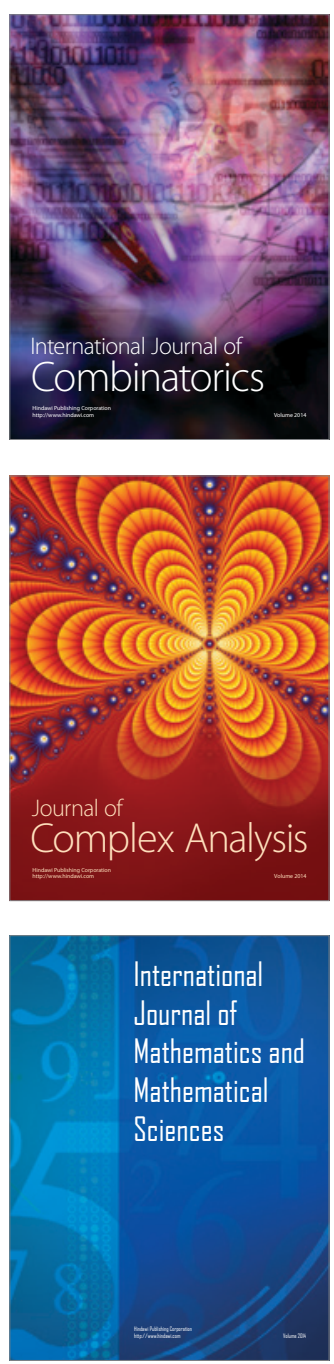
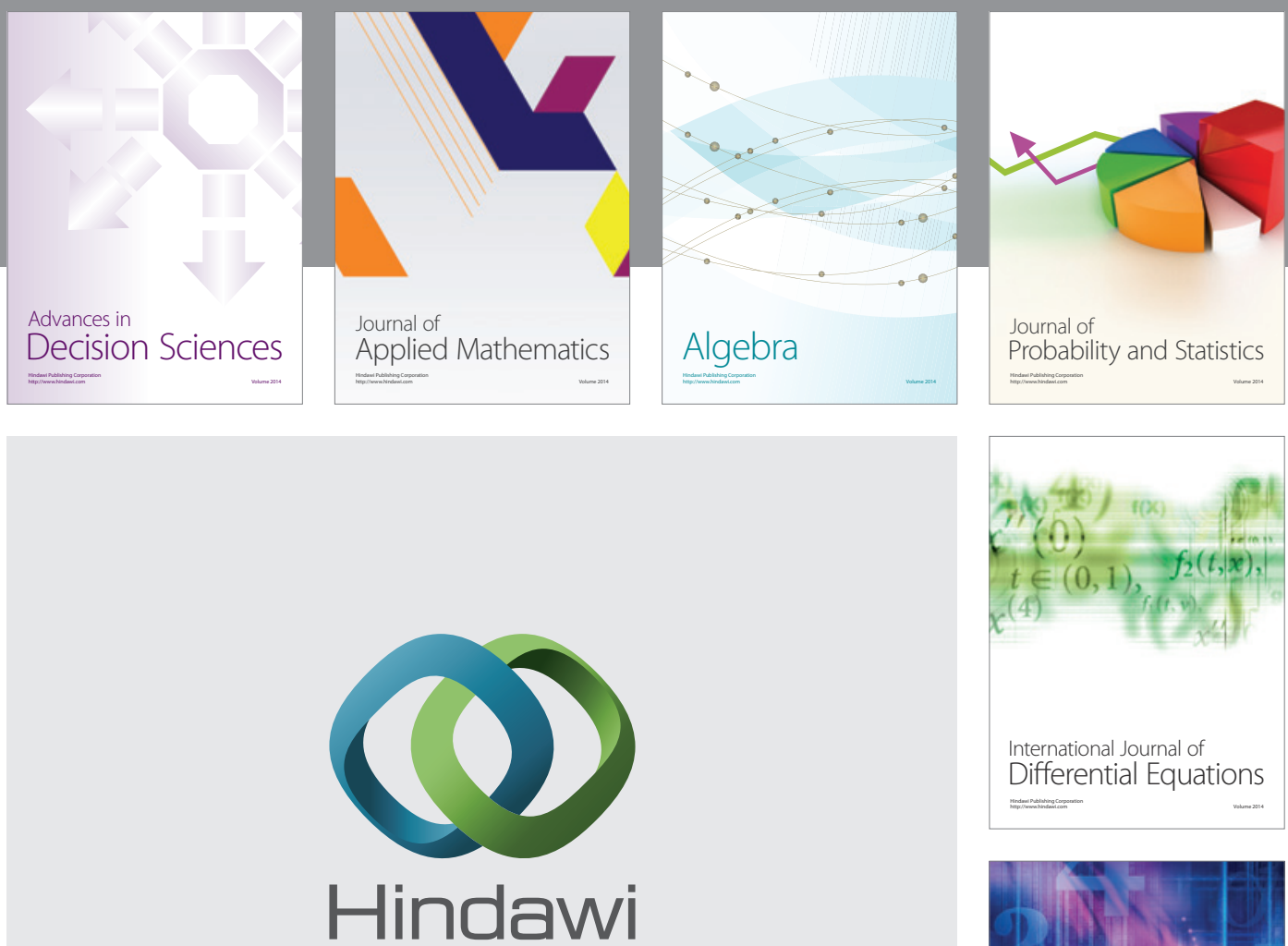

Submit your manuscripts at http://www.hindawi.com
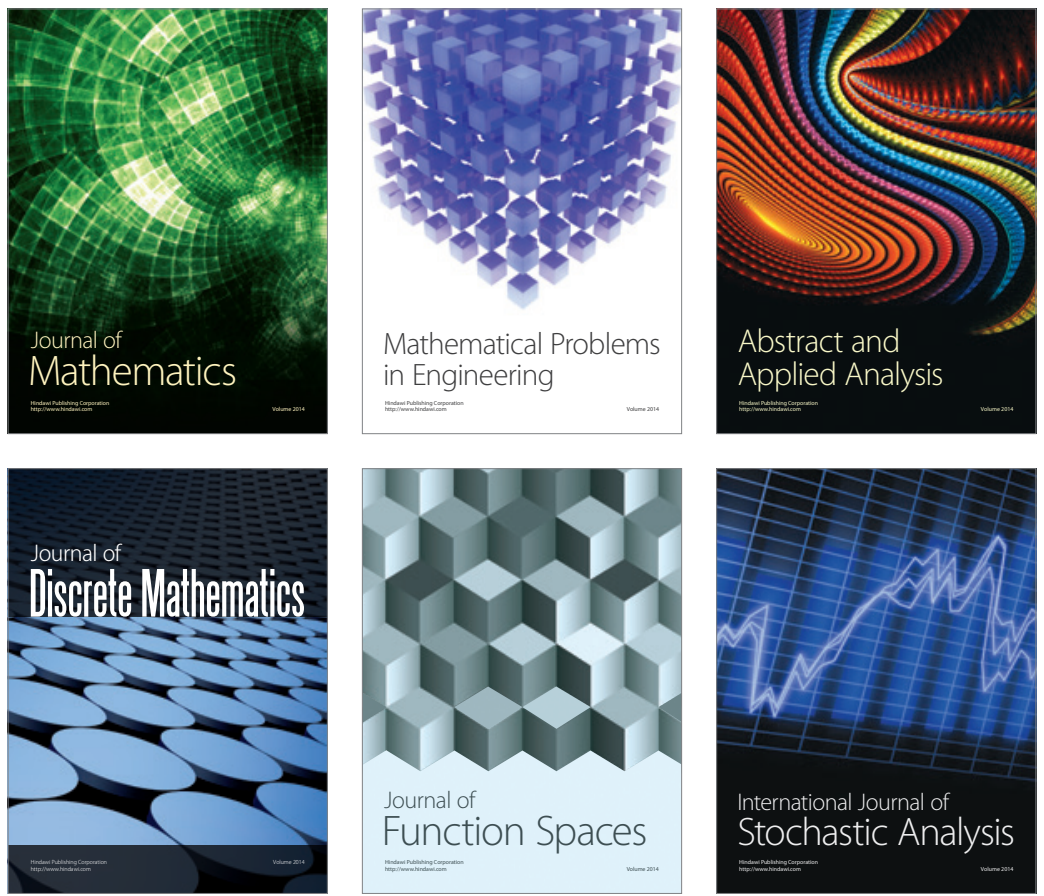

Journal of

Function Spaces

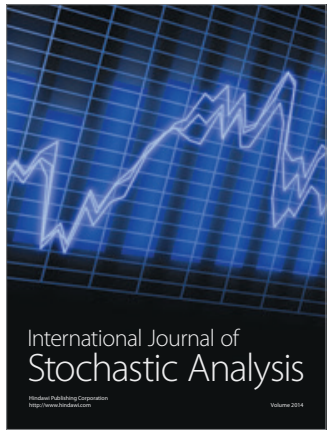

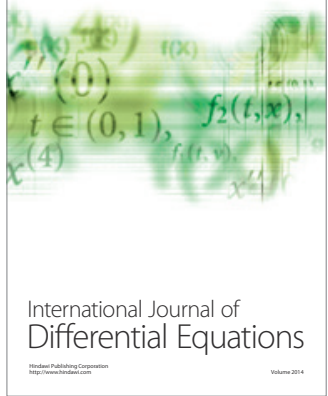
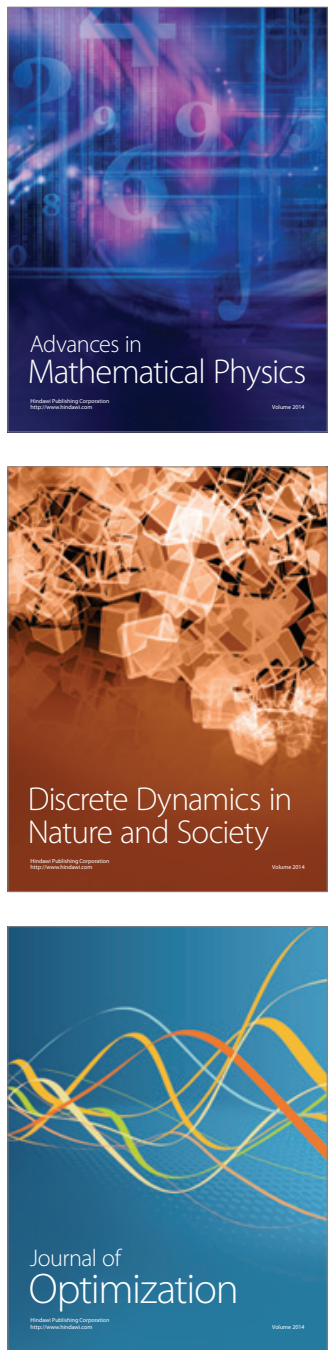